\title{
Pensar sem pressupostos: condição para problematizar o ensino da filosofia'
}

Rodrigo Pelloso Gelamo*

Resumo: Nossa proposta para este artigo é indicar, a partir da análise de alguns textos de Deleuze e Guattari, uma forma de escapar do modo tradicional de fazer filosofia, chamado pelos referidos autores de "modo maior". Nossa intenção é pensar uma possibilidade de problematização do ensino da filosofia que não se vincule às linhas majoritárias de pensamento filosófico ou educacional. Nesse sentido, mapearemos os pressupostos que a filosofia utiliza para começar a pensar filosoficamente e para enunciar seu discurso. Para isso, fundamentaremos nossa proposta na obra Diferença e repetição, de Gilles Deleuze (1968), especialmente no capítulo em que ele desenvolve as questóes sobre a "imagem do pensamento".

Palavras-chave: ensino da filosofia; filosofia francesa contemporânea; filosofia da diferença; Gilles Deleuze.

Thinking without presuppositions: a condition to problematize the teaching of philosophy

Abstract: Our proposal for this paper is to indicate, through the analysis of some of Deleuze's and Guattari's texts, an alternative to escape from the "traditional" way of doing philosophy, which these authors call a major mode. Our intention is to think of a possibility of questioning the teaching of philosophy that is not related to the majority trends of philosophical or educational thoughts. Thus, we will develop a study of the presuppositions used in philosophy to start thinking philosophically and to enunciate its speech. In order to do that, we will base our proposal on the book Difference and repetition, by Gilles Deleuze (1968), especially on the chapter in which he develops the issues concerning the images of thought.

Key words: philosophy teaching; contemporary French philosophy; philosophy of difference; Gilles Deleuze.

Para compreendermos como colocar um problema para o ensino da filosofia, torna-se necessário mapear o plano de composição no qual o saber filosófico se delineou, ou seja, mapear as intensidades que poderiam originar uma mu-

\footnotetext{
* Doutorando em Educação pelo Programa de Pós-Graduação da Universidade Estadual Paulista (Unesp) - Campus de Marilia, SP, Brasil. gelamo@gmail.com

।. Esta pesquisa é financiada pela Fundação de Amparo à Pesquisa do Estado de São Paulo (Fapesp).
} 
dança na "imagem do pensamento", instaurada no movimento da elaboração das formas teóricas que se produziram e se sedimentaram durante séculos. Para isso, procuraremos na obra de Gilles Deleuze e Félix Guattari um caminho que indicie uma atitude face ao pensamento filosófico para que possamos problematizar o ensino da filosofia diferentemente do modo como vem sendo usualmente problematizado. As condiçōes para essa forma de problematização talvez possam ser encontradas no modo "menor" de nos relacionarmos com o mundo.

O conceito de "menor" é apresentado principalmente em Mil Platôs (1980), mas já havia sido enunciado antes em Kafka: por uma literatura menor (1977), lugar onde foi engendrado. Encontramos na obra de Deleuze e Guattari a configuração de um "modo de problematização" que nos permitiu ter uma atitude filosófica face às questôes colocadas pela filosofia que tem como foco o ensino da filosofia. Nossa hipótese é a de que essa atitude possa ser elaborada a partir do conceito deleuzo-guattariano de "menor": uma "literatura menor" (1977; 1995b), uma "organização menor" (1995), "modo menor" na música (1995a), uma "ciência menor" (1995b; 1997b) ou "nômade" (1997b), "lugar menor" (1997b), uma "geometria menor" (1997b), "arte menor" (1997b). A essa lista poderíamos agregar um fazer menor na filosofia, o que nos permitiria pensar diferentemente o problema do ensino da filosofia, inventando problemas que o interpelem de outro modo. Neste contexto, a proposta de Deleuze e Guattari reside na criação de uma relação de "tensionamento" com a "filosofia maior", uma posição de resistência às "imagens do pensamento" instituídas e às linhas majoritárias do "fazer" filosófico.

A crítica ao fazer "maior" da filosofia pode ser encontrada na obra Diferença e repetição (1968), em que Deleuze mapeia os "pressupostos" da filosofia. Para ele, existem dois tipos de pressupostos: os objetivos e os subjetivos. Os pressupostos objetivos, utilizados pela ciência e pela filosofia, são supostos em um teorema, em um conceito ou em um problema; sua função é a de servir de "lei", funcionando como "aquilo que inquestionavelmente todos deveriam saber". Por exemplo: o homem é um animal racional é um pressuposto que, na sua evidência conceitual, não decorre de um modo de elaboração do sujeito. Por seu lado, os pressupostos subjetivos são aqueles que necessitam de uma elaboração do raciocínio para sua conceituação, ou seja, eles não são explicitamente dados. Exemplo disso é o "eu penso" cartesiano, cuja formulação necessita de uma elaboração do pensamento, de modo a demonstrar explicitamente que não é possível escapar da constatação de que pensamos e, por isso, somos (Deleuze, 1968).

Para Deleuze, a filosofia pretende escapar o máximo possível dos pressupostos objetivos, de modo a problematizar a consistência da sua objetividade. No 
entanto, ela dificilmente consegue escapar dos pressupostos subjetivos. Um dos exemplos dessa dificuldade enunciada por Deleuze pode ser encontrado no modo argumentativo pelo qual Descartes procura escapar do pressuposto objetivo dado pela afirmação de que todo homem é racional, não conseguindo, todavia, escapar do pressuposto subjetivo cuja forma se encontra na explicitação dos argumentos que têm como resultado o cogito ergo sum.

Segundo Deleuze,

Quando a filosofia assegura seu começo sob pressupostos implícitos ou subjetivos, ela pode, portanto, bancar (jouer) a inocente, pois nada guardou, salvo, é verdade, o essencial, isto é, a forma desse discurso. Então ela opõe o "idiota" ao pretensioso (pédant), Eudoxo a Epistemon, a boa vontade ao entendimento excessivo, o homem particular dotado tão- somente de seu pensamento natural ao homem pervertido pelas generalidades de seu tempo. A filosofia se coloca do lado do idiota como um homem sem pressupostos. Mas, na verdade, Eudoxo não tem menos pressupostos que Epistemon; ele apenas os tem só que sob outra forma, implícita ou subjetiva, "privada" e não "pública", sob a forma de um pensamento natural que permite à filosofia parecer (se donner l'air) começar e começar sem pressupostos. $(1968, \text { p. 170) })^{2}$.

Desse modo, a filosofia esconde-se sob a alegação de que não tem pressupostos. Contudo, muitas vezes ela os utiliza em sua elaboração do filosofar, seja como um pressuposto teleológico (como fim a ser alcançado) ou como um pressuposto metodológico (como meio de se filosofar). Para compreendermos melhor o funcionamento da "filosofia maior", refletiremos mais detidamente sobre o capítulo de Diferença e repetição (1968) no qual Deleuze se dedica a pensar a "Imagem do pensamento".

No referido capítulo, Deleuze sintetiza os oito postulados do pensamento que compóem os pressupostos da imagem do pensamento da filosofia: o princípio da Cogitatio universalis, o ideal do senso comum, o modelo da recognição, o elemento da representação, o negativo do erro, o privilégio da designação, a modalidade das soluções e o resultado do saber. Podemos dizer que, quando a filosofia utiliza esses postulados, ela se coloca como uma filosofia maior, pois se vincula aos estratos e às correntes de pensamento majoritárias, as quais, segundo Deleuze, poderiam ser caracterizadas pela imagem ortodoxa, dogmática, pré-filosófica, natural e moral do pensamento.

2. As traduções das citações dos originais franceses foram nossas. 
Nossa intenção é apresentar os "postulados do pensamento" criticados por Deleuze com a finalidade de compreender o funcionamento da filosofia maior e, assim, perspectivar as vias possíveis para escapar da dogmatização que a caracteriza. Procuramos, desse modo, evidenciar o espaço de circunscrição de uma "filosofia maior", para pensar a possibilidade de se fazer uma filosofia menor do e no ensino da filosofia.

No primeiro postulado da "imagem do pensamento" - "o princípio da cogitatio natura universalis" - Deleuze versa sobre o pressuposto de que haveria, no ser humano, uma "boa vontade" para o pensar e uma "boa natureza" do pensamento. Esse pressuposto funciona como um princípio natural no qual o pensamento se pautaria para fundamentar o seu processo de esclarecimento como predisposição não só para o pensar, mas, sobretudo, para o pensar bem. Esse princípio é formulado por Deleuze da seguinte maneira: "Muitos têm interesse em dizer que todo mundo sabe 'isto', que todo mundo reconhece isto, que ninguém pode negar isto.” (1968, p. 171). Esse pressuposto versa sobre três pilares que constituiriam os valores de verdade implícitos naquilo que se diz: o saber, o reconhecer e a impossibilidade em se negar.

Partindo desses princípios, o filósofo (ou aquele que pensa) seria guiado por aquilo que lhe é natural: o exercício de pensar. Através desse exercício natural, o homem caminharia em direção ao verdadeiro. Pouco importa se o ponto de partida do filosofar é o objeto ou o sujeito; o que muda é apenas a focalização num desses elementos, pois o pressuposto do que seja pensar e, conseqüentemente, do que seja filosofar, afigura-se como aquilo que permanece. Esse pressuposto funciona, então, como uma imagem pré-filosófica do filosofar que, em seu fazer, não questiona aquilo que se tem como universalmente aceito: o homem pensa e todos sabem o que é pensar, e, por sua natureza, sabem o que é importante ser pensado.

Deleuze recupera Nietzsche para afirmar que esse tipo de pensamento é um tipo de "pensar moral", pois, "só a Moral é capaz de nos persuadir de que o pensamento tem uma boa natureza e o pensador, uma boa vontade, e só o Bem pode fundar a suposta afinidade do pensamento com o Verdadeiro.” (1968, p. 172). Para escapar desse postulado, é necessário que a filosofia questione aquilo que lhe é pressuposto - todas as suas imagens pré-filosóficas - e liberte o pensamento de qualquer imagem que o determine. Tudo se passa "Como se o pensamento só pudesse começar, e sempre recomeçar, a pensar ao se libertar da imagem e dos postulados" (Deleuze, 1968, p. 173).

Para Deleuze, seria necessário problematizar, então, aquilo que é universalmente aceito pela filosofia e que ela extrai de forma pura do senso comum: que todos pensam e sabem o que é pensar. Assim, ele considera necessária uma "má 
vontade" ${ }^{\prime 3}$ perante a aceitação de qualquer imagem pré-concebida, ou seja, seria necessária uma atitude de recusa face à participação nesse bom senso para que a reversão dos pressupostos da cogitatio natura universalis se torne possível. Se não escaparmos dessa imagem do pensamento - que se tornou a imagem de direito para a filosofia -, não poderemos propor nenhuma outra forma de pensar. A questão do direito ao pensamento, que a filosofia retira do senso comum sem problematizá-lo, é desenvolvida por Deleuze no segundo postulado do pensamento.

No segundo postulado - "o ideal do senso comum" -, ao afirmar que "Todo mundo' bem sabe que, de fato, os homens pensam raramente e o fazem mais sob o impacto de um choque do que no elã de um gosto" (1968, p. 173), Deleuze ironiza sobre os pressupostos de que todo o homem pensa, de que pensar se constitui como "exercício natural" de uma faculdade e de que, de fato, existe no homem uma boa vontade para o pensamento. Segundo ele, pressupor que o pensar faz parte da natureza humana parece dar ao homem não só a possibilidade de encontrar o verdadeiro, mas também uma afinidade natural com a verdade. Poder-se-ia, no entanto, objetar que a filosofia não possui uma atitude passiva para com o senso comum, pois questiona a todo o momento essa afinidade do pensamento com o verdadeiro, revelando os seus contra-sensos. Todavia, aquilo que ela realmente questiona é a falta de lógica, de métodos e de rigor na argumentação que permitiria alcançar justificadamente a verdade de um determinado fato, e não o direito ao pensamento como condição natural do homem. A partir desse pressuposto, a filosofia encadeia uma série de outros pressupostos que visam à legitimação e ao entendimento de como pensamos e de como devemos pensar, sem se preocupar com a problemática ontológica do pensamento.

Para mostrar como o pensamento se desenvolve na sua relação com o conhecer ("re-conhecer"), o terceiro postulado - "o modelo da recognição" - toma como ponto de partida o pressuposto universalmente aceito de que "todos pensam". Assim, "o modelo da recognição" "se define pelo exercício concordante de todas as faculdades sobre um objeto supostamente o mesmo: é o mesmo

3. Quando Deleuze recorre à noção de má vontade (mauvaise volonté), remete-se a "alguém, mesmo que seja apenas um, com a modéstia necessária, que não chega a saber o que todo mundo sabe e que nega modestamente o que todo mundo supostamente reconhece. Alguém que não se deixa representar e que também não quer representar quem quer que seja. Não um particular dotado de boa vontade e de pensamento natural, mas um singular cheio de má vontade, que não chega a pensar, nem na natureza e nem no conceito. Apenas ele não tem pressupostos. Só ele efetivamente começa e efetivamente repete. Para ele, os pressupostos subjetivos não são menos preconceitos do que os objetivos; Eudoxo e Epistemon são um só e mesmo homem enganador, de quem é preciso desconfiar" (Deleuze, 1968, p. 17I). 
objeto que pode ser visto, tocado, lembrado, imaginado, concebido..." (Deleuze, 1968, p. 174). Essa confluência das faculdades sobre um objeto traz em seu interior o "reconhecimento" como resultado da concordância entre elas, tendo em vista a identidade desse mesmo objeto. Nesse sentido, a recognição conserva aquilo que é essencial como pressuposto: o modelo do bom, do belo, do verdadeiro, do importante, etc. e recorre a esses modelos para encontrar soluções para os problemas, tranqüilizando o pensamento: com esse pressuposto, o pensamento "reconhece" o que é importante pensar, por que é importante pensar, de que modo se deve pensar aquilo que é importante pensar e o que é necessário pensar para atingir o ideal do pensamento. A recognição estaria, então, marcada pela "representação" que tem por pressuposto a "identidade" como fundamento do pensamento.

A questão da representação vai ser objeto de uma reflexão mais demorada no quarto postulado - O "elemento da representação". Para Deleuze, a representação não permite ao pensamento diferenciar-se de seus pressupostos. A única possibilidade de diferenciação estaria na relação entre o "mesmo" e o "semelhante" e entre o "análogo" e o "oposto". Partindo desses quatro elementos, o pensamento representativo re-apresentaria uma série de conceitos que se diferenciariam apenas em grau, e não em natureza. Nesse sentido, a representação contribuiria para que os pressupostos do pensamento se mantivessem sempre os mesmos, variando apenas entre os dois extremos: entre aquilo que é análogo e aquilo que é oposto. Além de não garantir o pensamento como diferença em si mesma - uma vez que pensa a diferença sempre em relação a algo do qual o pensado se diferenciou -, o problema da representação está em tratar a diferença como erro ou como falsa representação.

O problema do erro é, por seu lado, abordado especificamente no quinto postulado - O "negativo" do erro. Segundo Deleuze, "O erro é o 'negativo' que se desenvolve naturalmente na hipótese da Cogitatio natura universalis" (1968, p. 194). O erro vem de uma falsa representação - uma falha no bom senso que toma o senso comum de forma bruta - caracterizada por uma falha na percepção e pelo falso reconhecimento. Esse aspecto já tinha sido desenvolvido por Descartes, nas Meditaçôes metafísicas, ao tratar das falsas percepções e dos erros dos sentidos. Assim, o erro não é intrínseco ao pensamento, mas, ao contrário, causado por algo que lhe é externo. Essa falha na percepção produziria um encadeamento "negativo" no processo de pensamento, pois o conduziria a falsas resoluções. Desse modo, a imagem dogmática do pensamento reduz o erro à figura do negativo (a besteira, a maldade e a loucura seriam reduzidas a essa figura), não aceitando as várias formas de pensar como um "pensar diferente".

Para explicar a problemática do erro face à designação, no sexto postulado "o privilégio da designação" - Deleuze utiliza como exemplo um professor que 
pede a um aluno para fazer um trabalho sobre determinado assunto. Segundo ele, nesse tipo de tarefa apenas é possível encontrar não-sensos, imprecisōes, abordagens desinteressantes, observações sem importância e, principalmente, perda de sentido. Não é, no entanto, possível encontrar erros no resultado. O problema é que o erro entra pela porta dos fundos, porque a filosofia atribui à proposição um valor de verdade, considerando-a como condição do verdadeiro. O sentido encontraria na recognição da própria proposição a sua verdade e também o seu erro. Assim, para Deleuze,

Remetendo o verdadeiro e o falso à relação de designação na proposição, dá-se um sexto postulado, da própria proposição ou da designação, que recolhe os precedentes e se encadeia com eles (a relação de designação é somente a forma lógica da recognição) (1968, p. 199-200).

O problema desse postulado é que a verdade e a falsidade do sentido estariam reduzidas à proposição e à sua relação com um fato extraproposicional. A verdade e a falsidade estariam, assim, na adequação possível entre a coisa e a proposição, ou seja, na representação possível de ser feita a partir da proposição acerca da coisa. A verdade é, então, o resultado empírico da relação entre a designação e o designado. $\mathrm{O}$ próprio modo de colocar a questão nesse tipo de filosofar já seria uma forma de adequação entre ambos. O problema, se pensarmos a partir dessa imagem dogmática do pensamento, é sempre dado antecipadamente e a resposta é uma busca entre as várias possibilidades de solução. Nesse modo de pensar, o agravante é que, uma vez dada a solução, o problema desaparece, perde sua força e sua função. O pensar seria, então, a busca de soluções para os problemas dados e seria apenas concernente às soluções e não à colocação dos problemas.

Isso nos remeteria ao sétimo postulado da imagem do pensamento - $D a$ modalidade das soluçôes. Sobre esse postulado Deleuze afirma:

\footnotetext{
Fazem-nos acreditar, ao mesmo tempo, que os problemas são dados já prontos (tout faits) e que eles desaparecem nas respostas ou na solução; sob este duplo aspecto, eles seriam, de início, nada mais que fantasmas (fantômes). Fazem-nos acreditar que a atividade de pensar, e também o verdadeiro e o falso em relação a esta atividade, só começam com a procura de soluções, só concernem às soluções. (1968, p. 205).
}

Nesse sentido, o problema dessa imagem dogmática estaria em não permitir que os próprios problemas sejam formulados, engendrados como uma atividade do pensamento, que o ato de pensar se constitua na colocação de problemas que afetam o pensamento daquele que pensa. A filosofia parece ser devedora de 
uma atitude comum que normalmente é utilizada para responder às perguntas duras de serem respondidas: o desvio de atenção. Essa atitude visa a deslocar a atenção daquilo que realmente foi perguntado e que soa como um problema que não tem solução ou como um problema banal, sendo, por isso, considerado como um falso problema. Muitas vezes, quando nos é colocada uma pergunta para a qual não se tem resposta, utilizamos o subterfúgio de invalidar a pergunta, considerando que o modo correto de colocá-la deveria ser outro. Assim, reconfiguramos o problema "original", adequando-o aos problemas cuja resposta já é sabida. Tornamo-nos escravos das perguntas já formuladas na história do pensamento; escravos porque nos tiram o direito às perguntas, o direito de as colocarmos da forma como as experimentamos, do modo como somos afetados pelos problemas. O que torna essa imagem mais problemática é a inversão entre a questão e a resposta. As questões são colocadas em função das respostas. Isto é, os problemas são colocados em função das suas possíveis respostas, sejam elas prováveis ou esperáveis. Kohan, comentando Deleuze, observa que

\begin{abstract}
A imagem dogmática apenas consegue construir as interrogações que as possíveis respostas permitem suscitar. Sob esta imagem, só se pergunta o que se pode responder. Considera-se que pensar tem a ver com encontrar soluções - já prefiguradas - aos problemas colocados em função de tais soluçóes e que os problemas desaparecem com suas soluções. Assim, se situa o problema como obstáculo e não como produtor de sentido e de verdade no pensamento. (2003, p. 222).
\end{abstract}

Os problemas e as soluções têm, nesse caso, a mesma natureza. A diferença entre eles consistiria apenas no modo de enunciação: o modo interrogativo (no caso dos problemas) e o modo explicativo ou proposicional (no caso das soluções). Partindo dessa análise, Deleuze afirma que os problemas e as soluçóes não podem ter a mesma natureza, apesar de estarem intrinsecamente ligados: a solução só encontra seu sentido no problema a ela subjacente. Se, por um lado, os problemas possuem um caráter universal, por outro, as soluçôes (que podem ser várias) são uma forma particular de resolução do problema. Isso impede que as resoluções possuam um caráter abstrato e universal.

Todas as vezes que o problema é colocado, as resoluçōes precisam ser novamente re-elaboradas e re-articuladas. Desse modo, os problemas não desaparecem nas soluções, mas se mantêm distintos e insistentes no movimento de invenção de novas soluçôes. No entanto, isso só é possível se os problemas não forem dados, se forem inventados e reinventados nas e com as soluções. Os problemas manifestariam, assim, uma natureza insistente, enquanto as soluções exerceriam uma força contrária cuja natureza procuraria determinar, particularizar e singularizar esses mesmos problemas. Sob esta perspectiva, os pro- 
blemas passam a desestabilizar as respostas e fazem com que elas se movimentem, impedindo-as de se tornarem abstrações universalizantes.

Se as questōes dadas não permitem a abertura da problematização, como poderiam elas ser formuladas? Para Deleuze, precisaríamos pensar os problemas em sua relação direta com os signos problemáticos. São os signos que, na sua força, violentam o pensamento. Assim, entramos no último dos oito postulados da imagem do pensamento - "O resultado do saber". Nesse postulado, ele desenvolve a relação entre o "problema", o "saber" e o "aprender". A relação entre o problema e o aprender é diferente da relação que pode ser estabelecida entre o problema e o saber. Se, na primeira relação, a afecção pelos signos é determinante para a invenção de uma enunciação dos problemas pelo aprendiz (esses problemas podem ser tanto práticos quanto especulativos), na segunda relação, o saber é determinado pela posse de uma regra ou de um método que define as soluções em função dos problemas dados. Essa posse inibiria a invenção enunciativa, dobrando a força problemática a uma adequação enunciativa aos problemas dados.

Para vincar uma diferenciação entre o "saber" e o "aprender", partiremos da análise de uma situação específica em que se desenvolve a relação entre o "problema", a "aprendizagem" e o "saber": a condução de um automóvel. Quando se tem a intenção de ser o condutor de um veículo, precisa-se ter a habilidade de dirigir. Essa habilidade implica um aprendizado que não se restringe ao uso do raciocínio lógico-dedutivo. Ao contrário, ela envolve uma relação que supõe não só uma articulação complexa entre o uso da razão e os reflexos motores, mas também um sublinhar da importância destes últimos, a fim de responder prontamente às necessidades de troca de marcha, aceleração, frenagem e reação ao perigo. Desse ponto de vista, não basta uma relação de saber face ao dirigir, mas, diferentemente, é necessário "aprender a dirigir". Assim, "Aprender é o nome que convém aos atos subjetivos operados face à objetividade do problema” (Deleuze, 1968, p. 213-214). Em si mesmo, o saber pode ser adquirido com a leitura e a assimilação das informações presentes no manual de instruções do condutor. Nele são apresentadas as referências a todas as funções e comandos do carro, a todos os cuidados que o condutor precisa ter. E, para aprofundar o saber, pode-se comprar uma cartilha que explique como dirigir em 10 liçôes, ou ainda pesquisar e escrever uma tese sobre a condução de um automóvel. A pessoa que passa por essa situação é um "sabedor" do que "é dirigir", o que não significa necessariamente ter aprendido a dirigir. Nessa segunda situação, o "saber designa apenas a generalidade do conceito ou a calma posse de uma regra das soluçôes" (Deleuze, 1968, p. 214). Assim, o conceito de formação, e o conceito de ensino dele derivado, pode ser questionado. Nesse sentido, aprender é 
[...] conjugar pontos relevantes de nosso corpo com pontos singulares da Idéia objetiva para formar um campo problemático. Esta conjugação determina para nós um limiar de consciência ao nível do qual nossos atos reais se ajustam às nossas percepções das relações reais do objeto, fornecendo, assim, uma solução do problema. (Deleuze, 1968, p. 214).

O mesmo tipo de aprendizado ocorre com o pensamento: não há como aprender a pensar utilizando uma cartilha dos 10 passos para aprender a pensar, e não se passa a pensar melhor com um manual dos 10 passos para se pensar bem. O método não garante o pensamento, mas apenas regula as faculdades, enquadrando-as na repetição de formas de pensar. Nesse sentido, não há método para se aprender a pensar, mas há apenas um adestramento das faculdades em função da repetição de fórmulas. Para Deleuze, o

Aprender é apenas o intermediário entre não-saber e saber, a passagem viva de um a outro. [...] a aprendizagem recai, sobretudo, do lado do rato no labirinto, enquanto que o filósofo fora da caverna leva consigo apenas o resultado - o saber - para dele extrair (dégager) os princípios transcendentais. (1968, p. 215).

Poderíamos dizer que, para Deleuze, quando a filosofia se vincula a essas imagens dogmáticas do pensamento, ou quando o filósofo se vincula às linhas majoritárias dos temas e problemas históricos, ela se enquadra no "modo maior" de filosofar. Essa vinculação não permite a produção da "diferença”, seja no pensamento, nos problemas ou nas soluções. No entanto, a filosofia pode ser feita de um "modo menor" quando problematiza linhas de intensidade que não se vinculam àquilo que "uma maioria" problematiza, escapando das imagens dogmáticas do pensamento. Segundo a leitura de Cardoso Jr., para Deleuze,

[...] toda filosofia é "menor" ou "minoritária”, desde que ela se desvincule das grandes linhas de senso comum, consideradas majoritárias, que nutrem uma opinião em torno de uma certa centralidade reconhecida como evidente, para uma maioria ou mesmo para uma minoria. (2006, p. 19).

O fazer "menor" da filosofia não remeteria, então, para a quantidade de pessoas que a fariam, mas para o modo de posicionamento que se assume face aos problemas. "Maior" e "menor" não seriam qualificações (bom/mau) ou quantificações (muito/pouco). Remeteriam antes para a função e para o tipo de uso que se faz da filosofia. Nesse sentido, poderíamos ser uma minoria que aborda certo tema de um modo filosófico determinado e ainda estar vinculados a uma filosofia maior, ou ser uma maioria que faz um uso menor da filosofia. $\mathrm{O}$ 
que distinguiria a filosofia maior da menor é o modo como cada uma se relaciona com o fazer filosófico.

Assim, a filosofia maior vincula-se ao poder das suas próprias constantes e luta pela manutenção das mesmas, enquanto a filosofia menor se vincula às potências da variação e do escapar dos centros aglutinadores dessas constantes (Deleuze; Guattari, 1980). Poderíamos dizer, então, que a "filosofia maior" é aquela que está instaurada e sedimentada historicamente pelo poder de sua inércia e que teria o poder de enunciar os problemas e propor soluções "dignas da filosofia". Nesse sentido, a marca da "filosofia maior" seria a busca pela unidade da representação, pela universalidade dos conceitos, pelo uso correto da razão, pela boa vontade do pensamento e do pensador.

A "filosofia menor", por seu lado, teria como proposta a transvaloração da filosofia maior por meio da potência da variação (diferenciação). Nesse sentido, o que importa para esse fazer filosófico são a multiplicidade, a singularidade, a idiotia e a má-vontade, características que fariam a filosofia menor escapar das relações de força aglutinadoras da repetição do mesmo problema, das mesmas soluções. A filosofia menor seria, assim, uma política de resistência aos padrôes instituídos do filosofar, do aprender e do ensinar.

A partir da caracterização feita por Deleuze e Guattari a respeito da filosofia maior, podemos afirmar que as produções sobre o ensino da filosofia vinculamse a esse modo de filosofar. Notamos isso principalmente quando nos deparamos com os problemas debatidos pela filosofia que trata do ensino da filosofia. Tais problemas são os mesmos encontrados como constantes na história do pensamento, desde Sócrates, ou, mais precisamente, desde o Platão da Polithéia, e retomados de forma mais pontual por Kant e por Hegel ${ }^{4}$ : a importância, os conteúdos e o método de se ensinar a filosofia. Poder-se-ia objetar que o ensino da filosofia, conforme apresentamos, é um problema menor para a filosofia, e não um problema maior.

Pensamos, no entanto, que esse problema não pode ser caracterizado como menor, mas precisa considerado pela filosofia como sendo de menor importância, uma vez que o modo de tratamento do problema do ensino da filosofia não se distingue do ato de filosofar, a não ser pelo tema. Portanto, não é o fato de abordar um problema de menor importância que faz das pesquisas sobre o ensino da filosofia uma filosofia menor, mas é a relação que esse fazer filosófico estabelece com a filosofia maior que faz dela tão maior quanto a filosofia maior.

4. Essa discussão pode ser encontrada nos trabalhos de Horn (2006), Novelli (2005), e Pagni (2002), os quais, de certa forma, evidenciam as preocupações desses autores com relação ao ensino da filosofia. Ver, também, Hegel (199|). 
Pode-se afirmar que, no Brasil, o problema do ensino da filosofia é amplamente debatido na atual conjuntura. No entanto, os problemas debatidos estão circunscritos por três preocupaçóes que norteiam as pesquisas: (1) o entendimento da importância do ensino da filosofia para a sociedade, para a cultura e para a formação crítica do homem; (2) a reflexão sobre os temas importantes a serem ensinados e sobre o currículo; e (3) a procura por uma metodologia do ensino da filosofia e do ensino do filosofar. Poderíamos dizer, então, que existem três imagens do pensamento através das quais a sua ortodoxia é circunscrita; elas são o espaço no qual aqueles que se dedicam a pensar o ensino da filosofia poderiam se enquadrar e enquadrar suas pesquisas. Esses seriam os lugares comuns a partir dos quais a filosofia do ensino da filosofia se coloca para filosofar. Para fazer uma filosofia menor, capaz de uma atitude menor face ao presente do ensino da filosofia, seria necessário seguir um caminho muito próximo ao que foi traçado por Deleuze e Guattari, ao tratarem da "língua maior":

Conquistar a língua maior para nela traçar línguas menores ainda desconhecidas. Servir-se da língua menor para por em fuga a língua maior. $\mathrm{O}$ autor menor é o estrangeiro em sua própria língua. Se é bastardo, se vive como bastardo, não é por um caráter misto ou mistura de línguas, mas antes por subtração e variação da sua, por muito ter entesado tensores em sua própria língua (1995b, p. 51. Grifos do autor).

A partir do pensamento deleuzo-guattariano (tanto daquilo que Deleuze produziu sozinho quanto daquilo que produziu em conjunto com Guattari), procuramos entender de que modo podemos propor um outro caminho de problematização face ao ensino da filosofia. Conforme dissemos anteriormente, a pesquisa sobre o ensino da filosofia estaria vinculada a um pensamento que procura debater os problemas enunciados como importantes, tentando mobilizar os pesquisadores para a sua resolução.

Nessa perspectiva, qualquer problematização ou pesquisa teria de estar vinculada à problemática de maior destaque no momento: o debate sobre a obrigatoriedade, a importância, os conteúdos e a metodologia do ensino da filosofia. Todavia, a partir do exposto, podemos seguir um outro caminho para pensar tal ensino. Um caminho que possa se inscrever em uma questão específica como esta: o que faz o filósofo quando seu oficio é ser professor de filosofia? Essa questão não é debatida no contexto atual talvez porque não se vincule às "imagens do pensamento" que ditam as questôes a serem debatidas sobre o ensino da filosofia. Pensamos que, além desta, outras questôes estão emergindo e evidenciando-se como um trabalho cauteloso de problematização e resistência aos pressupostos, um trabalho de resistência às forças que a filosofia maior exerce sobre nós. 


\section{Referências bibliográficas}

CARDOSO JR., Hélio Rebello. Pragmática menor: Deleuze, imanência e empirismo. 2006. (Livre docência). Universidade Estadual Paulista (Unesp). Campus de Assis.

DELEUZE, Gilles. Conversaçôes. Rio de Janeiro: Editora 34, 1992; Pourparlers. Paris: Minuit, 1990.

. Différence et répétition. Paris: PUF, 1968.

. Foucault. São Paulo: Brasiliense, 1988b.

. Proust e os signos. Rio de Janeiro: Forense Universitária, 1987.

DELEUZE, Gilles; GUATARI, Félix. Mil Platôs: capitalismo e esquizofrenia. Rio de Janeiro: Editora 34, 1995a. v. 1.

. Félix. Mil Platôs: capitalismo e esquizofrenia. Rio de Janeiro: Editora 34, 1995b. v. 2. . Félix. Mil Platôs: capitalismo e esquizofrenia. Rio de Janeiro: Editora 34, 1996. v. 3. . Félix. Mil Platôs: capitalismo e esquizofrenia. Rio de Janeiro: Editora 34, 1997a. v. 4. . Félix. Mil Platôs: capitalismo e esquizofrenia. Rio de Janeiro: Editora 34, 1997b. v. 5. . Félix. O que é a Filosofia? 2. ed. Rio de Janeiro: Editora 34, 1997.

DESCARTES, René. Obra escolhida. 3. ed. Rio de Janeiro: Bertrand Brasil, 1994.

HEGEL, Georg Wilhelm Friedrich. Discurso sobre educação. Lisboa: Edições Colibri, 1994. . Escritos pedagógicos. México: Fondo de Cultura Econômica, 1991.

HORN, Geraldo Balduino. Do ensino da filosofia à filosofia do ensino: contraposiçōes entre Kant e Hegel. In: http://www.anped.org.br/reunioes/26/trabalhos/geraldobalduinohorn.rtf Acesso em: 10/dez./2006.

KANT, Immanuel. Crítica da razão pura. Lisboa: Fundação Kalouste Gulbenkian, 1989. 1986. . Idéia de uma história universal de um ponto de vista cosmopolita. São Paulo: Brasiliense, . O conflito das faculdades. Lisboa: Edições 70, 1993.

. Que é o esclarecimento? (Aufkalärung). In: CARNEIRO LEÃO, E. (org). Immanuel Kant: textos seletos. Petrópolis: Vozes, 1985.

. Sobre a pedagogia. Piracicaba: Editora da Unimep, 1996.

KOHAN, Walter Omar. Infância. Entre filosofia e educação. Belo Horizonte: Autêntica, 2003.

NIETZSCHE, Friedrich. Além do bem e do mal. São Paulo: Companhia de Bolso, 2005. . Genealogia da moral: uma polêmica. São Paulo: Companhia das Letras. 1998.

NOVELLI, Pedro Geraldo Aparecido. O ensino da filosofia segundo Hegel: contribuições para a atualidade. Trans/Form/Ação, Marília, v. 28, n. 2, 2005. Disponível em: <http:// 
www.scielo.br/scielo.php?script=sci_arttext\&pid=S0101-31732005000200009 \&lng=en\&nrm=iso $>$. Acesso em: 12 mar 2007. Pré-publicação. doi: 10.1590/S010131732005000200009

PAGNI, Pedro Angelo. O ensino da filosofia nas obras de Kant, de Hegel e de Nietzsche: uma breve análise histórico-filosófica. In: Reflexão e Ação Revista do Departamento de Educação. UNISC, Santa Cruz do Sul. v.10, n.2, p. 111-135, jul./dez. 2002.

Recebido em 07 de fevereiro de 2008 e aprovado em 13 de junho de 2008. 